\title{
Importance of leptin signaling and signal transducer and activator of transcription-3 activation in mediating the cardiac hypertrophy associated with obesity
}

Maren Leifheit-Nestler ${ }^{1,2}$, Nana-Maria Wagner ${ }^{1,3}$, Rajinikanth Gogiraju' ${ }^{1}$, Michael Didié ${ }^{1,4}$, Stavros Konstantinides ${ }^{1,5}$, Gerd Hasenfuss $^{1}$ and Katrin Schäfer ${ }^{1 *}$

\begin{abstract}
Background: The adipokine leptin and its receptor are expressed in the heart, and leptin has been shown to promote cardiomyocyte hypertrophy in vitro. Obesity is associated with hyperleptinemia and hypothalamic leptin resistance as well as an increased risk to develop cardiac hypertrophy and heart failure. However, the role of cardiac leptin signaling in mediating the cardiomyopathy associated with increased body weight is unclear, in particular, whether it develops subsequently to cardiac leptin resistance or overactivation of hypertrophic signaling pathways via elevated leptin levels.

Methods: The cardiac phenotype of high-fat diet (HFD)-induced obese wildtype (WT) mice was examined and compared to age-matched genetically obese leptin receptor (LepR)-deficient (LepR ${ }^{\mathrm{db} / \mathrm{db}}$ ) or lean WT mice. To study the role of leptin-mediated STAT3 activation during obesity-induced cardiac remodeling, mice in which tyrosine residue 1138 within LepR had been replaced with a serine (LepR ${ }^{S 138}$ ) were also analyzed.

Results: Obesity was associated with hyperleptinemia and elevated cardiac leptin expression in both diet-induced and genetically obese mice. Enhanced LepR and STAT3 phosphorylation levels were detected in hearts of obese WT mice, but not in those with LepR mutations. Moreover, exogenous leptin continued to induce cardiac STAT3 activation in diet-induced obese mice. Although echocardiography revealed signs of cardiac hypertrophy in all obese mice, the increase in left ventricular (LV) mass and diameter was significantly more pronounced in LepR ${ }^{51138}$ animals. LepR ${ }^{\mathrm{S1138}}$ mice also exhibited an increased activation of signaling proteins downstream of LepR, including Jak2 (1.8-fold), Src kinase (1.7-fold), protein kinase B (1.3-fold) or C (1.6-fold). Histological analysis of hearts revealed that the inability of leptin to activate STAT3 in LepR $R^{\mathrm{db} / \mathrm{db}}$ and $\operatorname{LepR}^{\mathrm{S} 1138}$ mice was associated with reduced cardiac angiogenesis as well as increased apoptosis and fibrosis.

Conclusions: Our findings suggest that hearts from obese mice continue to respond to elevated circulating or cardiac leptin, which may mediate cardioprotection via LepR-induced STAT3 activation, whereas signals distinct from LepR-Tyr1138 promote cardiac hypertrophy. On the other hand, the presence of cardiac hypertrophy in obese mice with complete LepR signal disruption indicates that additional pathways also play a role.
\end{abstract}

Keywords: Heart, Hypertrophy, Leptin, Obesity, Signal transduction, STAT3

\footnotetext{
* Correspondence: katrin.schaefer@med.uni-goettingen.de

${ }^{1}$ Department of Cardiology and Pulmonary Medicine, Heart Research Center, Georg August University Medicine Goettingen, Robert Koch Strasse 40,

D-37075, Göttingen, Germany

Full list of author information is available at the end of the article
} 


\section{Background}

Obesity is frequently associated with elevated circulating leptin levels [1] and an increased risk to develop cardiac hypertrophy [2,3] or heart failure [4]. Clinical studies demonstrated a positive correlation between serum leptin levels and left ventricular (LV) mass or wall thickness [5,6], independent of blood pressure levels, suggesting a direct role for leptin in the pathogenesis of obesityassociated cardiomyopathy. Furthermore, leptin was shown to promote hypertrophy of isolated rat or human ventricular cardiomyocytes $[7,8]$, and this effect could be prevented using neutralizing antibodies [9].

Cardiac hypertrophy also develops in obese rodents fed high-fat diet (HFD) [10,11], and studies in mice with (functional) leptin deficiency suggested that the cardiac hypertrophy developing in states of chronic hyperleptinemia may result from the inability to transduce anti-hypertrophic and/or cardioprotective effects of the adipokine $[12,13]$. While the effects of leptin on cell shortening and intracellular $\mathrm{Ca}^{2+}$ transients were found to be abrogated in cardiomyocytes isolated from HFD-fed obese rats [14], others reported a preserved signal transduction in response to leptin in hyperleptinemic obese mice [15,16] or rats [17]. Thus, the role of the adipokine in mediating cardiac hypertrophy, in particular in the presence of elevated systemic leptin levels, and the possible existence of a cardiac leptin resistance in obesity remains unclear.

The leptin receptor (LepR) belongs to the family of cytokine type I receptors known to signal via activation of Janus kinase (Jak)-2 and signal transducer and activator of transcription (STAT)-3 [18]. Analysis of cardiomyocytes ex vivo revealed that leptin promotes hypertrophy via activation of p38 and p42/44 MAP kinases as well as protein kinase B (Akt) $[19,20]$. On the other hand, it is unknown whether STAT3 activation downstream of LepR is required to transmit the cardiac effects of leptin and whether it may be involved in mediating protective (i.e. anti-apoptotic, anti-fibrotic or pro-angiogenic) signals, as previously reported in mice with cardiomyocyte-specific STAT3 deletion $[21,22]$.

In this study, we examined the cardiac phenotype of diet-induced (i.e. with hypothalamic leptin resistance) and genetically obese (i.e. with systemic leptin receptor deficiency) hyperleptinemic mice, developing with age or after continuous $\beta$-adrenergic stimulation. Moreover, we determined the importance of leptin-mediated STAT3 activation for the development of cardiac hypertrophy in obesity by analyzing mice with targeted mutation of the STAT3 binding site within LepR.

\section{Methods}

\section{Animals}

C57B16/J leptin receptor-deficient $\mathrm{db} / \mathrm{db} \quad\left(\mathrm{LepR}^{\mathrm{db} / \mathrm{db}}\right.$; BKS.Cg Lepr ${ }^{\mathrm{db}} /$ Lepr $^{\mathrm{db}}$ ) mice and C57Bl6/J wildtype
(WT) controls were obtained from Harlan Winkelmann, Germany. Mice heterozygous mutant for the LepR ${ }^{\mathrm{S} 1138}$ allele (on the congenic B6.129/J background; 98- > 99\% homozygous for C57Bl/6; [23]) were obtained from Professor Martin Myers (University of Michigan Medical School, Ann Arbor, USA) and bred at the animal facility of the University of Goettingen, Germany, to generate homozygous mutant obese LepR ${ }^{\mathrm{S} 1138}$ mice. Age- and gender-matched WT $\left(\mathrm{LepR}^{+/+}\right.$) and heterozygous $\left(\mathrm{LepR}^{\mathrm{S} /+}\right)$ littermates were used as controls. To induce obesity, 3 months-old mice were switched to high-fat diet (HFD; D12451) for 4 months, while controls were maintained on normal rodent chow (D12450B; both Research Diets Inc.). The composition of both diets is shown in Additional file 1: Table S1. To examine the cardiac response to hypertrophic stimuli other than leptin, osmotic minipumps (Alzet ${ }^{\circ}$; model 2002; Charles River Laboratories) were filled with isoprenaline hydrochloride (Sigma; $20 \mathrm{mg} / \mathrm{kg}$ body weight $[\mathrm{BW}]$ per day) and implanted for 14 days under the dorsal skinfold of 2 months-old, $2 \%$ isoflurane anesthetized mice. At the time of tissue harvest, mice were weighed followed by intraperitoneal anesthesia with a mixture of $2 \%$ xylazine $(6 \mathrm{mg} / \mathrm{kg} \mathrm{BW})$ and $10 \%$ ketamine hydrochloride (100 mg/kg BW), and blood was drawn by cardiac puncture. Hearts were rapidly excised, the atria removed and ventricles immediately processed for protein isolation or cryoembedding, respectively. All animal care and experimental procedures had been approved by the institutional Animal Research Committee and complied with national guidelines for the care and use of laboratory animals.

\section{Serum analysis}

Freshly drawn blood was allowed to clot at room temperature (RT) for $30 \mathrm{~min}$, followed by centrifugation for $10 \mathrm{~min}$ at 3,000 rpm. The supernatant was stored at $80^{\circ} \mathrm{C}$ pending analysis of serum leptin levels using specific enzyme-linked immunoassays (ELISA; R\&D Systems).

\section{Echocardiography}

Echocardiography was performed by a blinded examiner at the day before tissue harvest in mice under 1.5\% isoflurane anesthesia using the VisualSonics Vevo 2100 system (Visualsonics) equipped with a $30 \mathrm{MHz}$ center frequency ultrasound transducer, as previously described [24]. M-mode echocardiographical recordings were used to determine the end-diastolic and end-systolic LV diameter (EDD and ESD, respectively) and the ventricular wall thickness (WTh), corresponding to the mean of the anterior and posterior WTh. LV mass was calculated using the formula: $1.055 \times\left([\mathrm{AWTh}+\mathrm{EDD}+\mathrm{PWTh}]^{3}\right.$ $\mathrm{EDD}^{3}$ ). Fractional shortening (FS) was calculated as $(E D D-E S D) / E D D \times 100$. B-mode echocardiography images were used to calculate the heart weight, using the 
equation: $1.05 \times(5 / 6) \times\left(\left(\mathrm{Epi}_{\text {syst }} \times\left(\mathrm{L}_{\text {syst }}+\left(\left(\mathrm{AWTh} \mathrm{s}_{\text {syst }}+\right.\right.\right.\right.\right.$ $\left.\left.\left.\left.\mathrm{PWTh}_{\text {syst }}\right) / 2\right)\right)\right)-\left(\right.$ Area $\left.\left._{\text {syst }} \times \mathrm{L}_{\text {syst }}\right)\right)$.

\section{Histology and immunohistochemistry}

Histochemical analyses were performed on $5 \mu \mathrm{m}$-thick frozen cross sections through the LV. For each mouse, 4 sections (approx. $500 \mu \mathrm{m}$ apart) and 4 randomly selected viewing fields (at 200-fold magnification) per section were analyzed and findings averaged. Cardiac fibrosis was determined after overnight incubation in Bouin's fixative followed by Masson's trichrome (MTC) stain. Monoclonal rat antibodies against mouse CD31 (Santa Cruz Biotechnology) were used to detect endothelial cells $[24,25]$. Their number was manually counted by a person blinded to the mouse genotype and expressed per $\mathrm{mm}^{2}$ or cardiomyocyte, respectively. Single cardiomyocytes were visualized by incubation with fluorescein-labeled wheat germ agglutinin (WGA; Molecular Probes), followed by determination of the cardiomyocyte cross-sectional area (CSA) using image analysis software (Image ProPlus). Per cross section, at least 10 randomly selected cardiomyocytes were evaluated and results averaged. Apoptosis was analyzed using the 'In Situ Cell Death Detection kit' (Roche). Cell nuclei were visualized using 4',6-diamidino-2-phenylindole (DAPI; Sigma).

\section{Immunoprecipitation and western blot analysis}

Frozen whole heart tissue (after removal of both atria) was pulverized on liquid nitrogen and resuspended in $500 \mu \mathrm{L}$ lysis buffer (1\% Triton-X 100, $150 \mathrm{mM} \mathrm{NaCl}$, $50 \mathrm{mM}$ TRIS, $5 \mathrm{mM}$ EDTA, pH 7.5) containing fresh protease $(4 \mu \mathrm{g} / \mathrm{mL}$ of each aprotinin, leupeptin and pepstatin A, $1 \mathrm{mM}$ PMSF) and phosphatase (20 mM $\mathrm{NaF}$ and $1 \mathrm{mM} \mathrm{Na}_{3} \mathrm{VO}_{4}$ ) inhibitors. After incubation for $20 \mathrm{~min}$ on ice, lysates were cleared by centrifugation at $13,000 \mathrm{rpm}$ for $10 \mathrm{~min}$ at $4^{\circ} \mathrm{C}$. Equal amounts $(50 \mu \mathrm{g})$ of protein were fractionated by SDS polyacrylamide gel electrophoresis together with molecular weight standards and transferred to nitrocellulose membranes (Protran ${ }^{\oplus}$, Whatman). Membranes were blocked in 1\% bovine serum albumine (in TBS, containing $0.1 \%$ Tween-20) prior to incubation with antibodies against phosphorylated (p)-Akt (S473) and total Akt, p-Jak2 (Y1007/1008) and total Jak2, p-p38 (T180/Y182) and total p38, p-p42/44 (T202/Y204) and total p42/44, p-Src (Y416) and total Src, p-STAT3 (Y705) and total STAT3, or p-PKC (pan), respectively (all Cell Signaling Technologies), or against leptin (R\&D Systems) and GAPDH (Biotrend), respectively. Protein bands were visualized using HRP-conjugated secondary antibodies (Amersham Biosciences), followed by detection with SuperSignal ${ }^{\odot}$ West Pico Substrate (Pierce). For the analysis of LepR phosphorylation, $100 \mu \mathrm{g}$ total heart tissue lysates were immunoprecipitated under rotation at $4^{\circ} \mathrm{C}$ with $2 \mu \mathrm{g}$ anti-
LepR antibody (against an internal domain present in the short and long isoforms of murine LepR; Santa Cruz Biotechnology) plus $50 \mu \mathrm{L}$ nProtein A Sepharose ${ }^{\mathrm{Tm}} 4$ Fast Flow beads (GE Healthcare) followed by detection of phosphorylated tyrosines (p-Tyr [PY20]; Santa Cruz Biotechnology) or LepR. For the analysis of STAT3 phosphorylation in response to acute elevations of circulating leptin, mice were fasted overnight, injected with recombinant murine leptin (1 mg/kg BW i.p.) and hearts harvested $30 \mathrm{~min}$ later. Protein bands were quantified by densitometry and results expressed as \% of total protein (after normalization for GAPDH expression).

\section{Statistical analysis}

Quantitative data are presented as mean \pm standard error of the mean (SEM). Normal data distribution was tested using the D'Agostino \& Pearson omnibus normality test. When three or more groups were compared, ANOVA was employed, if samples were normally distributed, or Kruskal-Wallis test, if not. For post-hoc comparisons, ANOVA was followed by Bonferroni's and Kruskal-Wallis by Dunn's multiple comparison test. Differences before and after isoprenaline infusion were tested using Student's $t$-test for paired means. Statistical significance was assumed when $\mathrm{P}$ reached a value less than 0.05. All statistical analyses were performed using GraphPad PRISM software, version 4.01 (GraphPad Software Inc).

\section{Results}

Clinical and experimental studies revealed that obesity is associated with LV hypertrophy [10,11], an important risk factor for the development of heart failure. As shown in Tables 1 and 2, WT mice fed HFD for 4 months (WT + HFD; mean body weight [BW], $44 \pm 1.9$ g) to induce obesity exhibited a non-significant trend towards an increased mean heart weight, LV mass and WTh compared to agematched lean controls fed normal chow (BW, 29 $\pm 1.0 \mathrm{~g}$ ). Marked LV hypertrophy was observed in 7 months-old obese LepR $\mathrm{R}^{\mathrm{db} / \mathrm{db}}$ mice (Table 1 and 2), consistent with a previous report [12]. Longitudinal sections through hearts of WT, WT + HFD and LepR ${ }^{\mathrm{db} / \mathrm{db}}$ mice are shown in Figure 1A, representative M-mode echocardiography recordings in Figure $1 \mathrm{~B}$ and cardiac cross-sections after WGA staining to delineate cardiomyocyte borders in Figure 1C. Of note, adiposity in mice with LepR deficiency was more pronounced compared to agematched WT + HFD mice (Table $1 ; \mathrm{P}<0.001$ ), in which obesity develops as result of hypothalamic resistance to chronically elevated leptin levels [26].

The presence of cardiac hypertrophy in LepR-deficient and, to a lesser extent also in diet-induced obese mice, suggests that it develops as a result of the heart's 
Table 1 Body, visceral fat and heart weights in 7 months-old mice

\begin{tabular}{|c|c|c|c|c|}
\hline & WT & WT + HFD & LepR $^{\mathrm{S1138}}$ & $\operatorname{LepR}^{\mathrm{db} / \mathrm{db}}$ \\
\hline $\mathbf{n}$ & 25 & 12 & 30 & 30 \\
\hline body weight $(\mathrm{g})$ & $29 \pm 1.0$ & $44 \pm 1.9^{* * *}$ & $54 \pm 1.1^{* * *} \# \# \#$ & $55 \pm 1.5^{* * *} \# \# \#$ \\
\hline VAT $(\mathrm{mg})$ & $0.6 \pm 0.1$ & $1.7 \pm 0.3^{*}$ & $3.3 \pm 0.3^{* * *} \# \# \#$ & $2.7 \pm 0.2^{* * *} \#$ \\
\hline serum leptin $(\mathrm{ng} / \mathrm{mL})$ & $12 \pm 1.3$ & $60 \pm 6.0^{* * *}$ & $67 \pm 5.9^{* * *} \S \S \S$ & $118 \pm 6.8^{* * *} \# \# \#$ \\
\hline heart weight (mg) & $135 \pm 3.6$ & $147 \pm 5.8$ & $212 \pm 11^{* * *} \# \# \# \S \S \S$ & $151 \pm 5.2$ \\
\hline normalized heart weight $(\mathrm{mg} / \mathrm{mm} \mathrm{TL})$ & $7.5 \pm 0.2$ & $8.2 \pm 0.3$ & $12 \pm 0.6^{* * *} \# \# \# \S \S \S$ & $8.9 \pm 0.2$ \\
\hline normalized heart weight $(\mathrm{mg} / \mathrm{g} \mathrm{BW})$ & $4.8 \pm 0.1$ & $3.4 \pm 0.2^{* * *}$ & $3.9 \pm 0.2^{* * *} \S \S \S$ & $2.8 \pm 0.1^{* * *}$ \\
\hline $\operatorname{CSA}\left(\mu \mathrm{m}^{2}\right)$ & $148 \pm 4.6$ & $161 \pm 6.4$ & $183 \pm 9.9^{* *}$ & $165 \pm 6.5$ \\
\hline
\end{tabular}

${ }^{*} \mathrm{P}<0.05$, ${ }^{* *} \mathrm{P}<0.01$ and ${ }^{* *} \mathrm{P}<0.001$ vs. WT mice; \#P $<0.05$ and \#\#\#P $<0.001$ vs. WT mice fed HFD; $\S \S \S \mathrm{P}<0.001$ for the difference between LepR ${ }^{\mathrm{S1138}}$ and LepR ${ }^{\text {db/ }}$

$\mathrm{db}$ mice. Abbreviations: BW, body weight; CSA, cross-sectional area; HFD, high-fat diet; $T L$, tibia length; VAT, visceral adipose tissue.

inability to respond to elevated systemic (Table 1 ) and/ or cardiac (Figure 2A) leptin levels. In this regard, Western blot analysis revealed increased levels of phosphorylated (p-) LepR (Figure 2B) and STAT3 (Figure 2C) protein in hearts of HFD-induced obese mice $(\mathrm{P}<0.05$ vs. WT for both), whereas findings in LepR $\mathrm{R}^{\mathrm{db} / \mathrm{db}}$ mice did not differ from those in lean controls or were reduced compared to those in WT + HFD mice $(\mathrm{P}<0.05$ for differences in LepR phosphorylation). Moreover, both lean and HFD-induced obese WT mice responded to a single i.p. injection of recombinant murine leptin with a significant increase in the cardiac STAT3 phosphorylation (Figure 2D), suggesting a preserved cardiac leptin signal transduction in hyperleptinemic, diet-induced obese mice.

To further study the role of leptin signaling in the development of cardiac hypertrophy and also to determine, whether the inability of leptin to activate STAT3 contributes to the cardiac maladaptation in obesity, we examined mice in which tyrosine (Tyr) 1138 within LepR had been replaced by a serine $\left(\mathrm{LepR}^{\mathrm{S1138}}\right)$. In these mice, leptin cannot signal via STAT3, but continues to be able to activate Jak2 and $\mathrm{SH} 2$ domain-containing adapter proteins. Western blot analysis revealed that $\mathrm{p}$-LepR (Figure 2B) and p-STAT3 (Figure 2C) levels in hearts of LepR ${ }^{\mathrm{S} 1138}$ mice did not significantly differ from those in WT and LepR $\mathrm{R}^{\mathrm{db} / \mathrm{db}}$ mice. Similar to mice with complete LepR deficiency, lack of LepR-mediated STAT3 activation resulted in severe adiposity, although serum leptin levels were lower than those in LepR $\mathrm{R}^{\mathrm{db} / \mathrm{db}}$ mice $(\mathrm{P}<0.001$; Table 1$)$. Interestingly, obese LepR ${ }^{\mathrm{S} 1138}$ exhibited a more pronounced increase in mean heart weights not only compared to lean or diet-induced obese WT mice, but also compared to $L e p R^{\mathrm{db} / \mathrm{db}}$ mice $(\mathrm{P}<0.001$ for all comparisons; Table 1), and differences persisted after normalization for body weight $(\mathrm{P}<0.001)$ or tibia length $(P<0.001)$. Echocardiography confirmed increased LV mass $(\mathrm{P}<0.01)$ or heart weights $(\mathrm{P}<$ $0.001)$ in LepR ${ }^{\mathrm{S} 1138}$ mice compared to their LepR ${ }^{\mathrm{db} / \mathrm{db}}$ counterparts (Table 2; please also see Figure 1A-C). Moreover, hearts of LepR ${ }^{\mathrm{S} 1138}$ mice exhibited elevated levels of phosphorylated Jak2 $(\mathrm{P}<0.001$ vs. WT; Figure 3A), Src kinase $(\mathrm{P}<0.05$ vs. WT, WT + HFD and LepR ${ }^{\mathrm{db} / \mathrm{db}}$; Figure $\left.3 \mathrm{~B}\right)$, Akt $\left(\mathrm{P}<0.001 \mathrm{vs}\right.$. LepR $\mathrm{R}^{\mathrm{db} / \mathrm{db}}$; Figure $3 C)$, PKC $\left(\mathrm{P}<0.05\right.$ vs. WT and $\mathrm{LepR}^{\mathrm{db} / \mathrm{db}}, \mathrm{P}<0.01$ vs. WT + HFD; Figure 3D) and p38 MAPK $(\mathrm{P}<0.01$ vs. LepR $^{\mathrm{db} / \mathrm{db}}$; Figure 3E), suggesting that an intact, Tyr1138independent LepR activation in the presence of elevated leptin levels may have contributed to the pronounced cardiac hypertrophy present in these mice. On the other

Table 2 Echocardiographic parameter in 7 months-old mice

\begin{tabular}{|c|c|c|c|c|}
\hline & WT & WT + HFD & LepR $^{\mathrm{S1138}}$ & $\operatorname{LepR}^{\mathrm{db} / \mathrm{db}}$ \\
\hline$\underline{n}$ & 25 & 12 & 30 & 30 \\
\hline heart rate $(\mathrm{bpm})$ & $463 \pm 6.5$ & $481 \pm 6.7$ & $459 \pm 10$ & $460 \pm 11$ \\
\hline WTh (mm) & $0.70 \pm 0.01$ & $0.75 \pm 0.02$ & $0.85 \pm 0.02^{* * *} \#$ & $0.81 \pm 0.02^{* *}$ \\
\hline ESD $(\mathrm{mm})$ & $3.2 \pm 0.1$ & $3.5 \pm 0.1^{*}$ & $3.2 \pm 0.1 \# \S \S$ & $3.0 \pm 0.1^{*} \# \# \#$ \\
\hline EDD $(\mathrm{mm})$ & $4.3 \pm 0.1$ & $4.5 \pm 0.1$ & $4.6 \pm 0.1^{* *} \S \S$ & $4.3 \pm 0.03$ \\
\hline LVM (mg) & $116 \pm 4.2$ & $132 \pm 5.8$ & $166 \pm 7.2^{* * *} \# \S \S$ & $137 \pm 5.5^{* *}$ \\
\hline HW (mg) & $118 \pm 3.3$ & $121 \pm 3.6$ & $135 \pm 4.6^{* *} \S \S \S$ & $108 \pm 2.0$ \\
\hline FS (\%) & $26 \pm 0.7$ & $22 \pm 0.8$ & $31 \pm 1.1^{*} \# \# \#$ & $31 \pm 0.9^{* *} \# \# \#$ \\
\hline
\end{tabular}

${ }^{*} \mathrm{P}<0.05$, ${ }^{*} \mathrm{P}<0.01$ and ${ }^{* * * \mathrm{P}}<0.001$ vs. WT mice; \#P $<0.05$ and \#\#\#P<0.001 vs. WT mice fed HFD; $\S \S \mathrm{P}<0.01$ and $\S \S \S \mathrm{P}<0.001$ for the difference between $L_{\text {LepR }}{ }^{\mathrm{S} 138}$ and LepR ${ }^{\mathrm{db} / \mathrm{db}}$ mice. Abbreviations: bpm, beats per minute; HW, calculated heart weight; EDD, end diastolic diameter; ESD, end systolic diameter; FS, fractional shortening; LVM, left ventricular mass; WTh, wall thickness. 
A
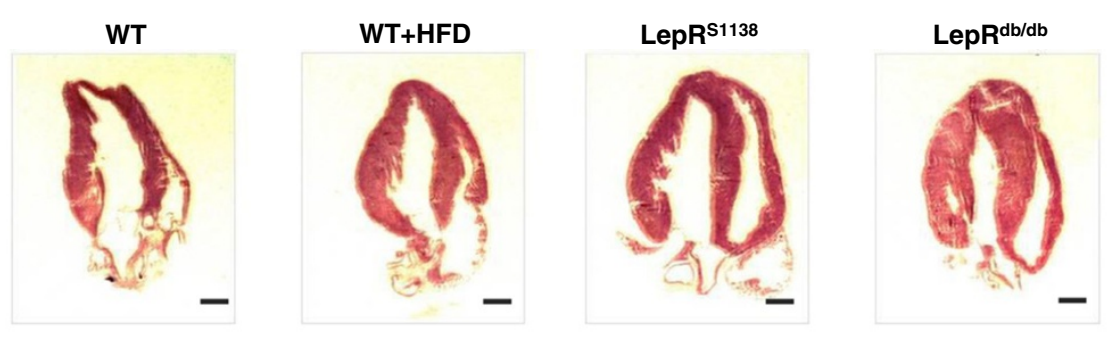

B
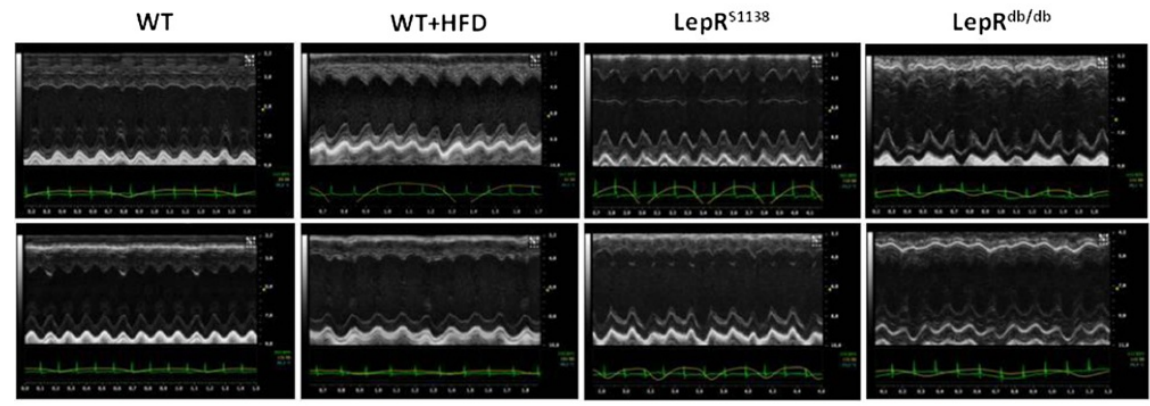

C
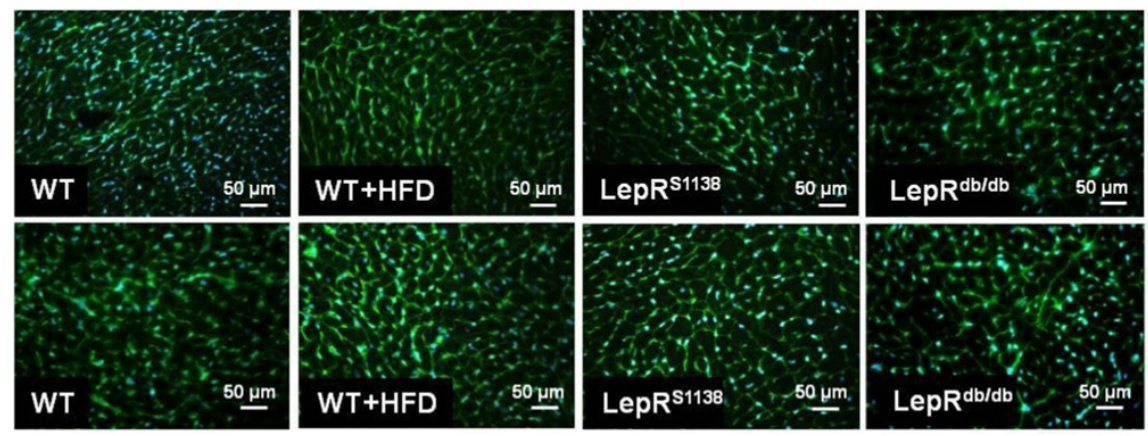

Figure 1 Cardiac phenotype of lean and obese WT, WT + HFD, LepR ${ }^{\mathrm{S1138}}$ and LepR ${ }^{\mathrm{db} / \mathrm{db}}$ mice. (A) Representative H\&E-stained longitudinal sections through hearts of 7 months-old mice are shown. Magnification, $\times 10$. (B) Representative M-mode echocardiographic recordings. (C) Representative images of wheat germ agglutinin (WGA)-stained myocardial cross sections. The mean cardiomyocyte cross-sectional areas are given in Table 1.

hand, cardiac levels of p-p42/44 MAPK did not significantly differ between the mouse groups (Figure 3F).

M-mode echocardiography also revealed significantly increased enddiastolic LV diameters in Lep $\mathrm{R}^{\mathrm{S} 1138}$ mice $\left(\mathrm{P}<0.01\right.$ vs. WT and LepR ${ }^{\mathrm{db} / \mathrm{db}}$ mice; Table 2; representative findings are shown in Figure 1B), suggesting that the observed (over-)activation of LepR signaling together with the inability to induce STAT3 may result in augmented hypertrophy and maladaptive cardiac remodeling. Of note, fractional shortening (FS) was not significantly altered in HFD-induced obese WT mice $(\mathrm{P}=$ n.s. vs. WT mice), but found to be increased in both $L e p R^{\mathrm{db} / \mathrm{db}}(\mathrm{P}<0.01$ vs. WT and $\mathrm{P}<0.001$ vs. WT + HFD mice) and LepR ${ }^{\mathrm{S} 1138}$ mice $(\mathrm{P}<0.05$ vs. WT and $\mathrm{P}<$ 0.001 vs. WT + HFD mice). Histological analyses revealed significantly reduced numbers of CD31-positive capillary endothelial cells in LepR $\mathrm{R}^{\mathrm{db} / \mathrm{db}}$, and to a lesser extent also in $\mathrm{LepR}^{\mathrm{S} 1138}$ mice (Figure 4A), whereas the number of TUNEL-positive apoptotic cells (Figure 4B) and the fibrotic tissue area (Figure 4C) were found to be significantly increased in hearts of both LepR ${ }^{\mathrm{S} 1138}$ and LepR $\mathrm{db}^{\mathrm{db}}$ mice compared to lean and diet-induced obese WT mice.

To examine the specificity of leptin's hypertrophic action in obesity, the cardiac response of young, i.e. 

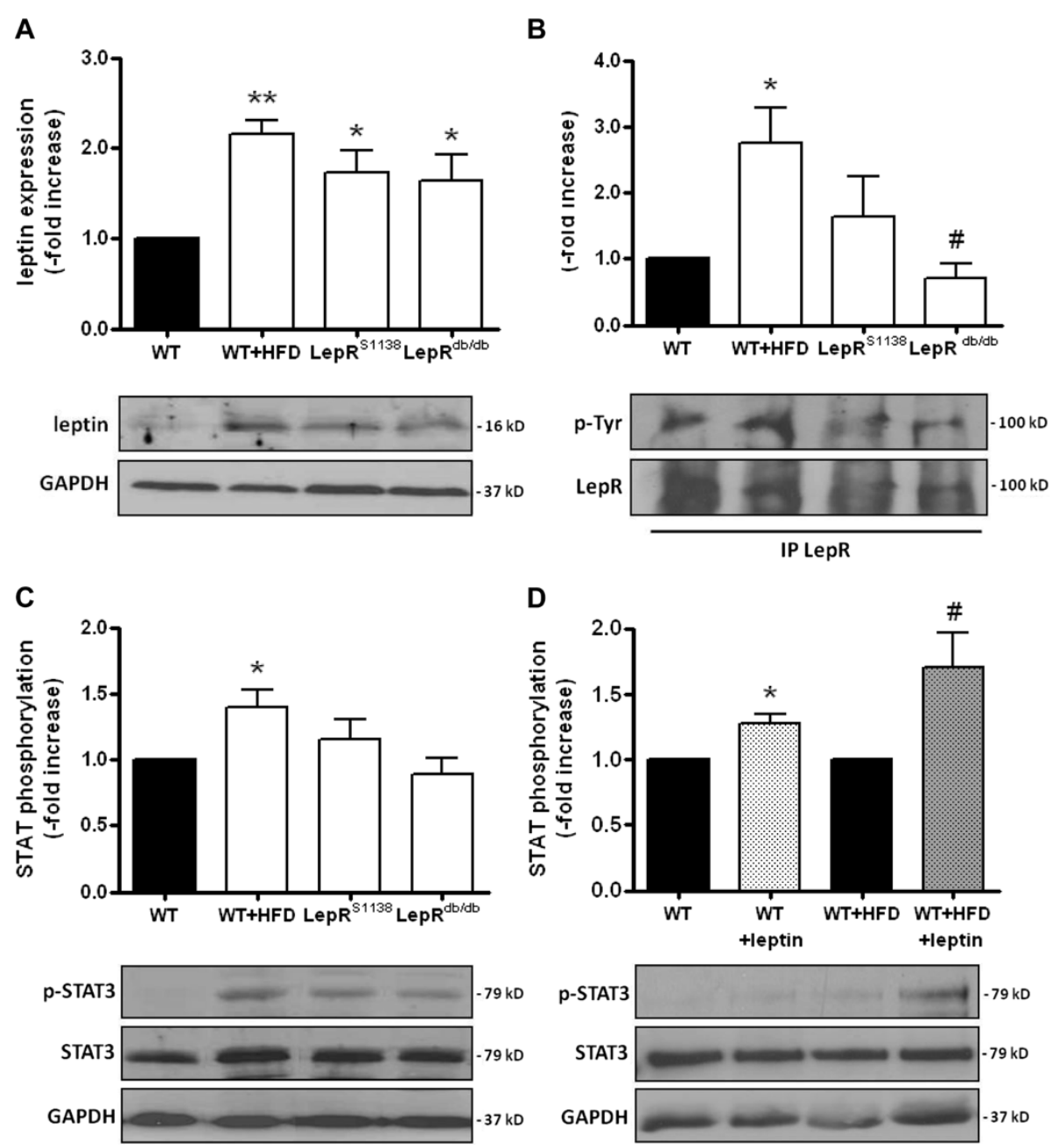

Figure 2 Cardiac leptin expression and signal transduction in lean and obese mice. Protein was extracted from hearts of 7 months-old mice ( $n=8$ per group) and analyzed for the expression of (A) leptin, (B) phosphorylated LepR (using immunoprecipitation of LepR, followed by the detection of total phosphotyrosines and LepR) and (C) phosphorylated STAT3. (D) Cardiac STAT3 phosphorylation in response (30 min later) to a single injection of recombinant murine leptin ( $1 \mathrm{mg} / \mathrm{kg}$ BW i.p.) was examined in WT $(n=4)$ and WT + HFD $(n=6)$ mice. Results are expressed as -fold increase of controls (black bars) after normalization for total protein and GAPDH expression. The mean \pm SEM as well as representative Western blot results are shown. ${ }^{*} \mathrm{P}<0.05$ and ${ }^{* *} \mathrm{P}<0.01$ vs. WT mice; $\# \mathrm{P}<0.05$ vs. WT + HFD mice.

2 months-old WT ( $\mathrm{n}=12$; body weight, $22 \pm 0.9 \mathrm{~g})$, LepR $^{\text {S1138 }}(\mathrm{n}=9 ; 34 \pm 1.1 \mathrm{~g}, \mathrm{P}<0.001$ vs. WT $)$ and $\operatorname{LepR}^{\mathrm{db} / \mathrm{db}}$ mice $(\mathrm{n}=7 ; 40 \pm 1.3$ g; $\mathrm{P}<0.001$ vs. WT and $\mathrm{P}<0.01$ vs. $\mathrm{LepR}^{\mathrm{S} 1138}$ ) to chronic isoprenaline infusion (20 mg/kg BW per day) was examined. Under basal conditions, similar findings as those in 7 months-old mice were observed, i.e. LepR ${ }^{\text {S1138 }}$ mice exhibited an increased heart weight $\left(\mathrm{P}<0.05\right.$ vs. LepR ${ }^{\mathrm{db} / \mathrm{db}}$; Figure $\left.5 \mathrm{~A}\right), \mathrm{LV}$ mass $(\mathrm{P}<$ 0.01 vs. WT; Figure $5 \mathrm{~B})$ and mean WTh ( $\mathrm{P}<0.05$ vs. WT; Figure $5 \mathrm{C}$ ), whereas other changes, such as differences in fractional shortening (Figure 5D), ESD (Figure 5E) and EDD (Figure 5F) were not (yet) detected. On the other hand, all mouse groups responded to chronic $\beta$-adrenergic stimulation with significant cardiac hypertrophy, and no differences (with the exception of heart weight; Figure 5A) were observed between LepR ${ }^{\mathrm{S} 1138}$ and LepR ${ }^{\mathrm{db} / \mathrm{db}}$ mice. Representative $\mathrm{M}$-mode echocardiography tracings are shown in Figure 6 and summarized in Additional file 2: Table S2.

\section{Discussion}

The adipocytokine leptin may link obesity with cardiac hypertrophy, an important risk factor for the development of heart failure. Studies in humans [2,3] and rodents $[10,11]$ have shown that obesity is associated with LV hypertrophy, and body mass index was identified as a strong and independent predictor of LV mass [2,3]. Importantly, cardiac hypertrophy is also observed in normotensive obese subjects [6], and plasma leptin levels 

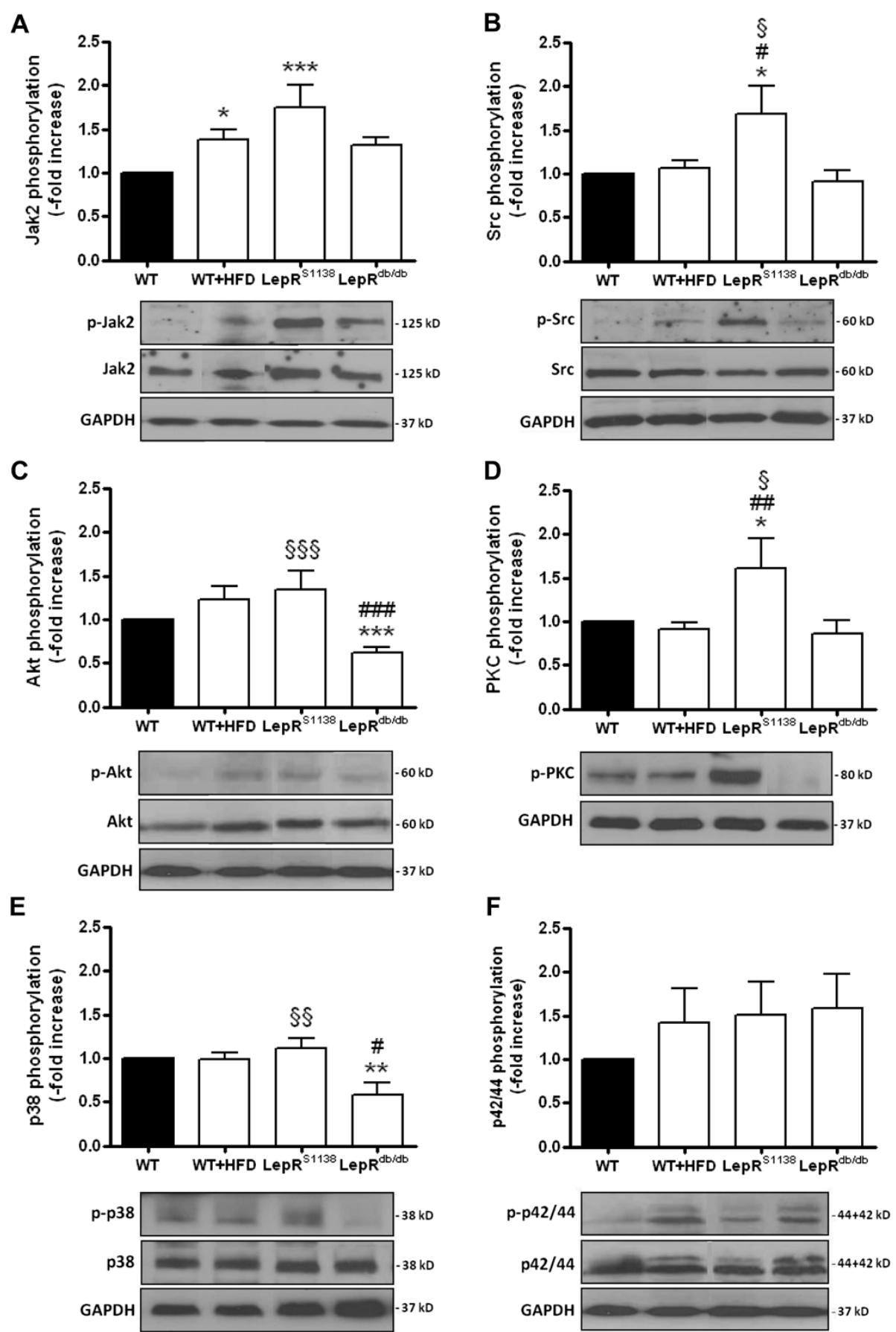

Figure 3 Hypertrophic signal transduction in hearts of lean and obese mice. Protein was isolated from hearts of 7 months-old WT ( $n=15$ ), WT + HFD ( $n=12)$, LepR ${ }^{\text {S1138 }}(n=15)$ and LepR $R^{\mathrm{db} / \mathrm{db}}(n=15)$ mice and analyzed for the expression of phosphorylated Jak2 (A), Src kinase (B), Akt (C), PKC (D), p38 (E) and p42/44 MAPK (F). Results are expressed as -fold increase of lean control mice (after normalization for total protein [with the exception of PKC] and GAPDH expression). The mean \pm SEM as well as representative findings are shown. ${ }^{* P}<0.05$, ${ }^{* * P}<0.01$ and ${ }^{* * * P}<$ 0.001 vs. WT mice; \#P $<0.05$ and \#\#P $<0.01$ vs. WT + HFD mice; $\S P<0.05, \S \S P<0.01$ and $\S \S \S P<0.001$ for the difference between LepR ${ }^{\mathrm{db} / \mathrm{db}}$ and LepR $^{\mathrm{S} 1138}$ mice.

are associated with increased myocardial wall thickness independent of BW or blood pressure elevations [5], suggesting a causal role for leptin in the pathogenesis of cardiac hypertrophy.
Although the major source of leptin is adipose tissue, cardiomyocytes are also capable of synthesizing leptin [27], and increased cardiac leptin levels have been reported in mice or rats following coronary ligation 


\section{A}
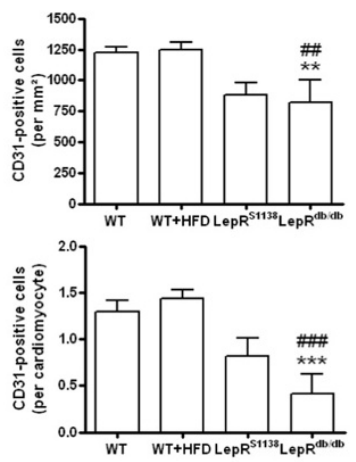

B

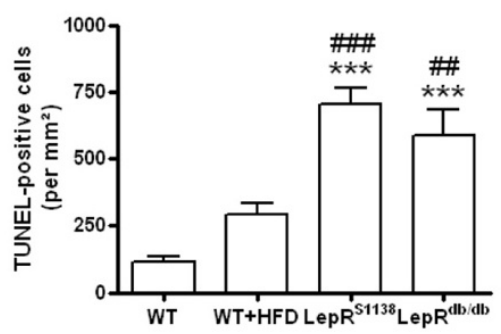

C

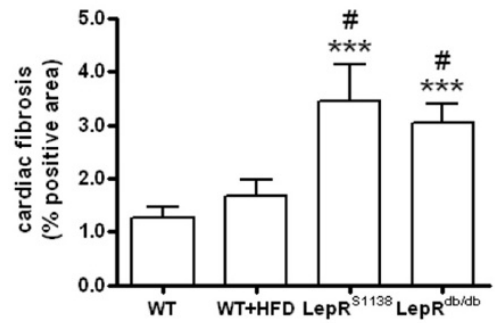

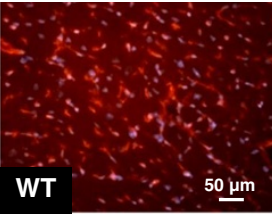
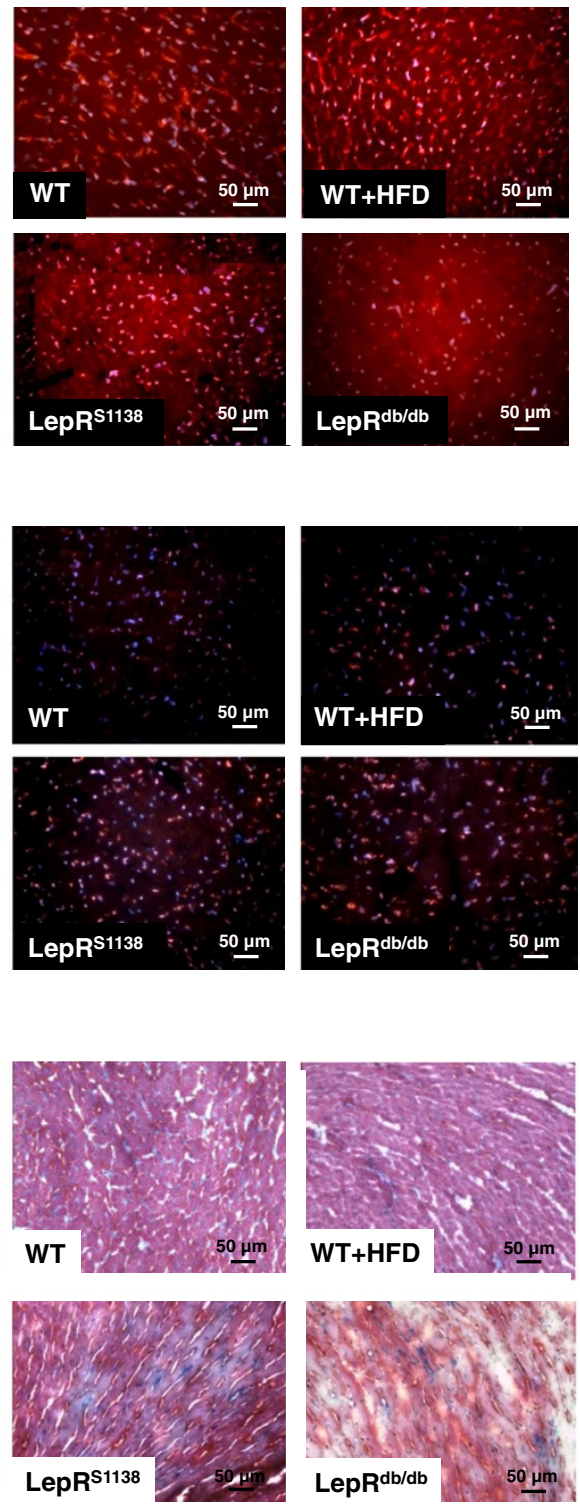

Figure 4 Histological analysis of angiogenesis, apoptosis and fibrosis in hearts of lean and obese mice. Serial cross sections through the LV of WT, WT + HFD, LepR ${ }^{51138}$ and LepR ${ }^{\mathrm{db} / \mathrm{db}}$ mice ( $\mathrm{n}=10$ per group) were immunostained and the number of (A) CD31-positive endothelial cells and (B) TUNEL-positive apoptotic cell nuclei determined. Results are expressed per cardiomyocyte and/or mm². (C) The degree of cardiac fibrosis was quantified after Masson's trichrome (MTC) staining. Results are expressed as \% of total tissue area (at 200-fold magnification). The

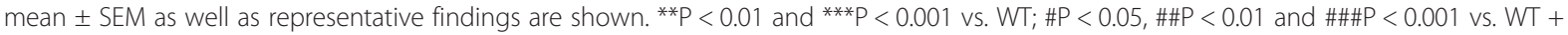
HFD mice.

$[13,18]$ or in patients with heart failure [28]. In this study, elevated circulating as well as cardiac leptin levels were detected in both diet-induced and genetically obese mice, which may have acted on cardiomyocytes as well as other, non-cardiomyocyte cells expressing leptin receptors [29]. Although leptin serum levels were higher than in previous publications [30], we explain this findings with the higher age of the mice, a factor previously found to be associated with increased circulating leptin levels [31]. Leptin has been shown to stimulate the hypertrophy of cardiomyocytes isolated from rats $[7,20]$ or humans [8,19]. Moreover, chronic leptin infusion increased cardiac ANP expression after myocardial infarction (MI) in mice [32], whereas neutralizing LepR antibodies abrogated the hypertrophy of the surviving myocardium after coronary artery ligation in rats [33]. On the other hand and as confirmed in our analysis, cardiac hypertrophy also develops in leptin- and LepR-deficient 

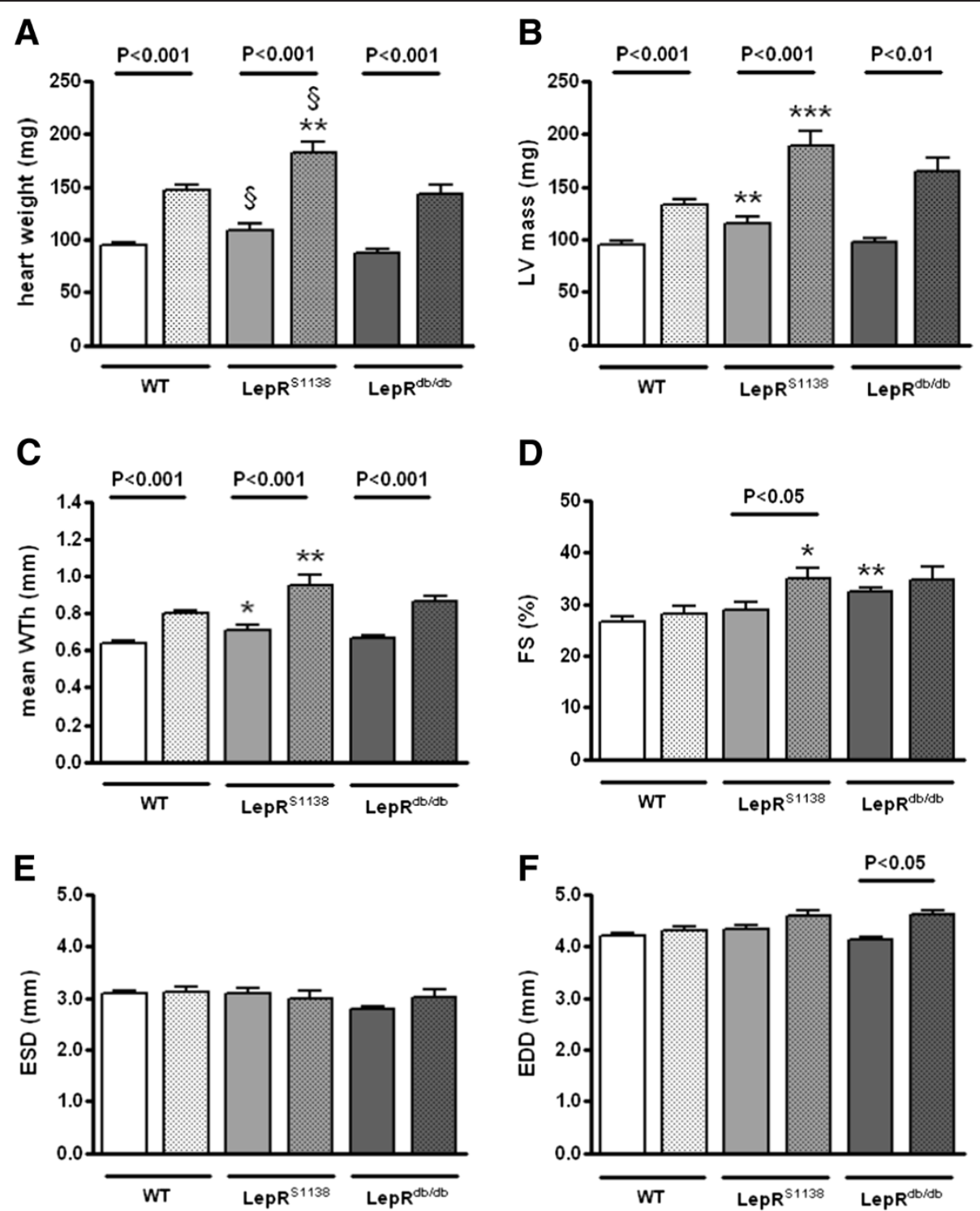

Figure 5 Echocardiography findings in young lean and obese mice before and after chronic $\beta$-adrenergic stimulation. Isoprenaline-filled osmotic minipumps were subcutaneously implanted into 2 months-old WT $(n=12)$, LepR $R^{S 1138}(n=9)$ and LepR $R^{\mathrm{db} / \mathrm{db}}(n=7)$ mice to examine the cardiac response to a hypertrophic stimulus other than leptin. Echocardiography (A-F) was performed immediately before (open bars) as well as at the time of tissue harvest 14 days later (dotted bars). ${ }^{*} \mathrm{P}<0.05$, ${ }^{*} \mathrm{P}<0.01$ and ${ }^{* *} \mathrm{*} P 0.001$ for differences Vs. WT mice; $\$ P<0.05$ for differences between LepR ${ }^{\mathrm{db} / \mathrm{db}}$ and LepR ${ }^{S 1138}$ mice. Significance levels for differences before and after isoprenaline stimulation (as determined using Student's $t$ test for paired means) are indicated within the graph.

mice and may be reversed by leptin substitution [12]. Caloric restriction experiments suggested that the antihypertrophic effects of leptin had occurred in addition to weight loss [12], which itself may preserve heart function and attenuate LV remodeling [34]. Thus, it is unclear whether the cardiac hypertrophy in obesity is the consequence of pro-hypertrophic effects of the adipokine or rather the result of a resistance towards leptin's preventive effects on hypertrophic cardiac remodeling. Of note, since body weight is markedly elevated in the diet-induced and particularly, the genetically obese mice, the heart-to-body weight ratio decreases, even though the absolute heart weight is increased (but to a relatively lesser extent).

Obesity is associated with elevated circulating leptin levels and hypothalamic resistance to the weightreducing effects of the adipokine, whereas the existence of a peripheral (e.g. cardiac) leptin resistance is controversial. For example, reduced cardiac LepR expression has been reported in HFD-fed rats [14], whereas others demonstrated unaltered cardiac STAT3 phosphorylation in diet-induced obese rodents following acute leptin administration [15-17]. Our findings also suggest that 

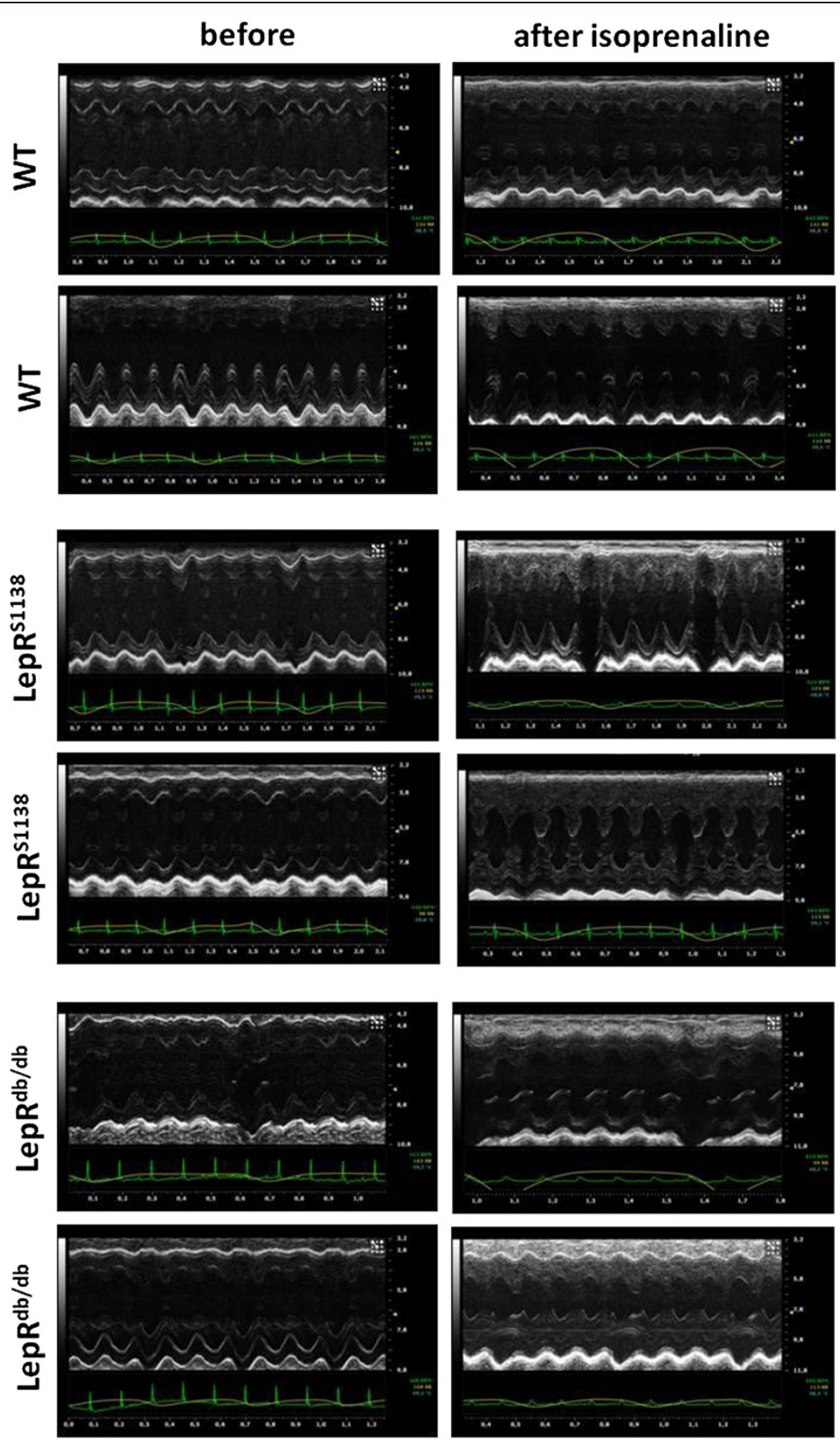

Figure 6 Representative M-mode echocardiography recordings.

hearts from diet-induced obese mice continue to respond to leptin in the presence of chronically elevated leptin levels and that the observed elevation of serum and cardiac leptin may thus contribute to the development of cardiac hypertrophy in obesity. For example, hearts of hyperleptinemic obese WT mice (i.e. those with intact leptin receptors) exhibited signs of activated leptin signaling, including elevated levels of phosphorylated LepR and STAT3, while they were unchanged or reduced in mice with mutated or truncated forms of
LepR (i.e. LepR ${ }^{\mathrm{S} 1138}$ or LepR ${ }^{\mathrm{db} / \mathrm{db}}$ mice). Moreover, both lean and obese WT mice responded to a single leptin injection with increased cardiac STAT3 phosphorylation. Of note, we could not spatially dissect the cardiac responsiveness to leptin, since whole heart homogenates were examined. Possible explanations underlying the discrepancy between the present and some previous studies include the animal species, as the absence of a response to leptin in obesity has been so far primarily observed in rats [14]. In addition, age, sex and feeding status of the 
animals or the time of recombinant leptin administration may have influenced the results. Of note, previous studies in humans have reported the existence of individuals (up to $40 \%$ ) exhibiting a blunted response to leptin [35], although it is unknown, whether such phenomenon also occurs in rodents.

Interestingly, hearts from LepR ${ }^{\mathrm{S} 1138}$ mice exhibited a marked overactivation of STAT3-independent leptin signaling pathways, including Jak2, Src kinase, Akt or p38 MAPK, i.e. factors previously shown to mediate the prohypertrophic effects of the adipokine in cardiomyocytes $[19,20]$. Importantly, overactivation of leptin signaling in hearts of LepR ${ }^{\mathrm{S} 1138}$ mice was accompanied by a pronounced cardiac hypertrophy, both at the organ and the single cardiomyocyte level, despite similar adiposity. Although leptin levels were found to be lower in LepR ${ }^{\text {S1138 }}$ compared to LepR $\mathrm{R}^{\mathrm{db} / \mathrm{db}}$ mice, as previously reported [23], leptin continues to be able to activate LepR signal transduction in these mice, for example via LepR-Tyr985. Similar echocardiographical findings were obtained in young (i.e. 2 months-old) and older (i.e. 7 months-old) mice, arguing against the development of cardiac hypertrophy secondary to hemodynamic or other metabolic changes associated with obesity, although we cannot exclude the possible contribution of a more pronounced hyperinsulinemia [23] to the development of cardiac hypertrophy in LepR ${ }^{\mathrm{S} 1138}$ mice. On the other hand, hypertension had not been observed in ob/ob mice [12], and heart weight increase and concentric LV hypertrophy in obese mice and humans also occurs without systolic and diastolic blood pressure elevations $[5,6,36]$.

Although a predominant cardiac expression of the short (i.e. without STAT3 binding site) over the long LepR isoform has been reported [7,29], previous studies have shown that stimulation of neonatal rat cardiomyocytes with leptin increased STAT3 phosphorylation, nuclear translocation and DNA binding activity [32]. Also, cardiac STAT3 activation after MI was blunted in leptin-deficient mice [13]. The observation that increased cardiac STAT3 phosphorylation in hyperleptinemic, diet-induced obese mice was reduced or almost completely abolished in LepR $^{\mathrm{S} 1138}$ or Lep $\mathrm{R}^{\mathrm{db} / \mathrm{db}}$ mice suggests that cardiac STAT3 activation in obesity largely occurs downstream of elevated leptin levels and that other cytokines, also elevated in obesity and known to signal via Jak2-STAT3, may be of minor importance. On the other hand, the importance of leptin-mediated STAT3 activation in the heart and its contribution to cardioprotective signaling pathways in vivo have not been directly examined so far.

STAT3 has been implicated in cardioprotection after various injuries. For example, cardiomyocyte-specific STAT3 deletion results in dilatative cardiomyopathy, characterized by increased apoptosis and interstitial fibrosis as well as reduced myocardial capillary density
$[21,22]$. Previous studies suggested that leptin may exert beneficial effects on the heart. For example, administration of leptin was associated with smaller infarct size after ischemia/reperfusion injury [37], whereas ischemic postconditioning failed to induce cardioprotection in mice lacking leptin or its receptor [38]. Also, leptin deficiency was associated with a worsened cardiac function and survival after coronary artery ligation, which could be improved by leptin repletion [13]. Regarding possible mechanisms, increased cardiac myocyte apoptosis was observed in hearts from leptin (receptor)-deficient mice $[39,40]$. Similar findings were obtained in vitro, showing that leptin protects cardiomyocytes against apoptotic cell death induced by serum starvation [41]. Our analyses also revealed significantly elevated numbers of apoptotic cells in hearts of obese LepR ${ }^{\mathrm{S} 1138}$ and $L e p R^{\mathrm{db} / \mathrm{db}}$ mice, consistent with a reduced activation of STAT3-responsive anti-apoptotic genes [40]. Although findings in mice with systemic defects in leptin signal transduction may have been confounded by the concomitant presence of obesity and associated metabolic and inflammatory alterations, adverse cardiac remodeling after MI [42] or lethal heart failure [43] were recently reported in mice with cardiomyocyte-specific LepR deletion. On the other hand, the beneficial effects of leptin-mediated STAT3 activation may not be restricted to cardiomyocytes. For example, we and others have shown that leptin promotes the angiogenic properties of endothelial (progenitor) cells $[25,44]$, and cardiac angiogenesis was reduced in $L e p R^{S 1138}$ and $\mathrm{LepR}^{\mathrm{db} / \mathrm{db}}$ mice. In addition, hearts of obese LepR $R^{\mathrm{S} 1138}$ and LepR $\mathrm{R}^{\mathrm{db} / \mathrm{db}}$ mice exhibited increased interstitial fibrosis, which may have occurred secondary to increased cardiomyocyte loss, although previous studies have shown that leptin may also directly influence myocardial matrix metabolism [45]. On the functional level, the enhanced activation of prohypertrophic signaling pathways in the absence of STAT3mediated cardioprotection may have contributed to the echocardiographic finding of LV cavity dilation in LepR $^{\text {S1138 }}$ compared to LepR ${ }^{\mathrm{db} / \mathrm{db}}$ mice.

\section{Conclusions}

Taken together, our findings suggest that hearts from diet-induced obese mice continue to respond to chronically elevated leptin levels and that increased systemic and/or local leptin and enhanced cardiac LepR activation contribute the development of cardiac hypertrophy. On the other hand, chronic overactivation of hypertrophic signaling mediators together with an inabilitity to activate STAT3-dependent cardioprotective pathways may promote maladaptive cardiac remodeling. Of note, our findings also indicate that leptin signaling is not a prerequisite to develop cardiac hypertrophy in obesity and 
that additional pathways also contribute to the increase in LV mass associated with higher body weight.

\section{Additional files}

Additional file 1: Table S1. Diet composition.

Additional file 2: Table S2. Echocardiographic parameter in 2 months-old mice before and 14 days after isoprenaline infusion.

\section{Competing interests}

The authors declare that they have no competing interests.

\section{Authors' contributions}

MLN and NMW carried out the protein and histological analyses of mouse hearts, performed the statistical analysis and drafted the manuscript. RG carried out and evaluated the TUNEL assays. MD aquired and analyzed the echocardiographical data. SK and GH participated in the design of the study and critically revised it for its contents. KS conceived and designed the study, wrote the manuscript, and aquired funding. All authors have read and approved the final manuscript.

\section{Acknowledgements}

The authors thank Sarah Barke and Anika Hunold for expert technical assistance. This work was supported by the German Research Foundation (Deutsche Forschungsgemeinschaft; Clinical Research Group, KFO 155) to K.S. and G.H..

\section{Author details}

'Department of Cardiology and Pulmonary Medicine, Heart Research Center, Georg August University Medicine Goettingen, Robert Koch Strasse 40, D-37075, Göttingen, Germany. ${ }^{2}$ Current address: Department of Pediatric Kidney, Liver and Metabolic Diseases, Hannover Medical School, Hannover, Germany. ${ }^{3}$ Current address: Clinic for Anesthesiology and Intensive Care Medicine, University Medicine Rostock, Rostock, Germany. ${ }^{4}$ Department of Pharmacology, Georg August University Medicine Goettingen, Goettingen, Germany. ${ }^{5}$ Current address: Center for Thrombosis and Hemostasis, University Medicine Mainz, Mainz, Germany.

Received: 25 January 2013 Accepted: 1 July 2013

Published: 11 July 2013

\section{References}

1. Considine RV, Sinha MK, Heiman ML, Kriauciunas A, Stephens TW, Nyce MR, Ohannesian JP, Marco CC, McKee $\sqcup$, Bauer TL: Serum immunoreactive-leptin concentrations in normal-weight and obese humans. N Engl J Med 1996, 334:292-295.

2. Gottdiener JS, Reda DJ, Materson BJ, Massie BM, Notargiacomo A, Hamburger RJ, Williams DW, Henderson WG: Importance of obesity, race and age to the cardiac structural and functional effects of hypertension. The department of veterans affairs cooperative study group on antihypertensive agents. J Am Coll Cardiol 1994, 24:1492-1498.

3. Lauer MS, Anderson KM, Kannel WB, Levy D: The impact of obesity on left ventricular mass and geometry. The framingham heart study. JAMA 1991, 266:231-236.

4. Kenchaiah S, Evans JC, Levy D, Wilson PW, Benjamin EJ, Larson MG, Kannel WB, Vasan RS: Obesity and the risk of heart failure. N Engl J Med 2002, 347:305-313.

5. Paolisso G, Tagliamonte MR, Galderisi M, Zito GA, Petrocelli A, Carella C, de Divitiis $O$, Varricchio M: Plasma leptin level is associated with myocardial wall thickness in hypertensive insulin-resistant men. Hypertension 1999, 34:1047-1052.

6. Perego L, Pizzocri P, Corradi D, Maisano F, Paganelli M, Fiorina P, Barbieri M, Morabito A, Paolisso G, Folli F, Pontiroli AE: Circulating leptin correlates with left ventricular mass in morbid (grade III) obesity before and after weight loss induced by bariatric surgery: a potential role for leptin in mediating human left ventricular hypertrophy. J Clin Endocrinol Metab 2005, 90:4087-4093.
7. Rajapurohitam V, Gan XT, Kirshenbaum LA, Karmazyn M: The obesity-associated peptide leptin induces hypertrophy in neonatal rat ventricular myocytes. Circ Res 2003, 93:277-279.

8. Madani S, De Girolamo S, Munoz DM, Li RK, Sweeney G: Direct effects of leptin on size and extracellular matrix components of human pediatric ventricular myocytes. Cardiovasc Res 2006, 69:716-725.

9. Rajapurohitam V, Javadov S, Purdham DM, Kirshenbaum LA, Karmazyn M: An autocrine role for leptin in mediating the cardiomyocyte hypertrophic effects of angiotensin II and endothelin-1. J Mol Cell Cardiol 2006, 41:265-274.

10. Fang CX, Dong F, Thomas DP, Ma H, He L, Ren J: Hypertrophic cardiomyopathy in high-fat diet-induced obesity: role of suppression of forkhead transcription factor and atrophy gene transcription. Am J Physiol Heart Circ Physiol 2008, 295:H1206-H1215.

11. Majane $\mathrm{OH}$, Vengethasamy L, du Toit EF, Makaula S, Woodiwiss AJ, Norton GR: Dietary-induced obesity hastens the progression from concentric cardiac hypertrophy to pump dysfunction in spontaneously hypertensive rats. Hypertension 2009, 54:1376-1383.

12. Barouch LA, Berkowitz DE, Harrison RW, O'Donnell CP, Hare JM: Disruption of leptin signaling contributes to cardiac hypertrophy independently of body weight in mice. Circulation 2003, 108:754-759.

13. McGaffin KR, Sun CK, Rager JJ, Romano LC, Zou B, Mathier MA, O'Doherty RM, McTiernan CF, O'Donnell CP: Leptin signalling reduces the severity of cardiac dysfunction and remodelling after chronic ischaemic injury. Cardiovasc Res 2008, 77:54-63.

14. Ren J, Zhu BH, Relling DP, Esberg LB, Ceylan-Isik AF: High-fat diet-induced obesity leads to resistance to leptin-induced cardiomyocyte contractile response. Obesity (Silver Spring) 2008, 16:2417-2423.

15. Somoza B, Guzman R, Cano V, Merino B, Ramos P, Diez-Fernandez C, Fernandez-Alfonso MS, Ruiz-Gayo M: Induction of cardiac uncoupling protein-2 expression and adenosine $5^{\prime}$-monophosphate-activated protein kinase phosphorylation during early states of diet-induced obesity in mice. Endocrinology 2007, 148:924-931.

16. Stucchi P, Guzman-Ruiz R, Gil-Ortega M, Merino B, Somoza B, Cano V, de Castro J, Sevillano J, Ramos MP, Fernandez-Alfonso MS, Ruiz-Gayo M: Leptin resistance develops spontaneously in mice during adult life in a tissue-specific manner. Consequences for hepatic steatosis. Biochimie 2011, 93:1779-1785.

17. Nascimento AF, Luvizotto RA, Leopoldo AS, Lima-Leopoldo AP, Seiva FR, Justulin LA Jr, Silva MD, Okoshi K, Wang XD, Cicogna AC: Long-term high-fat diet-induced obesity decreases the cardiac leptin receptor without apparent lipotoxicity. Life Sci 2011, 88:1031-1038.

18. Kloek C, Haq AK, Dunn SL, Lavery HJ, Banks AS, Myers MG Jr: Regulation of Jak kinases by intracellular leptin receptor sequences. J Biol Chem 2002, 277:41547-41555.

19. Tajmir P, Ceddia RB, Li RK, Coe IR, Sweeney G: Leptin increases cardiomyocyte hyperplasia via extracellular signal-regulated kinase- and phosphatidylinositol 3-kinase-dependent signaling pathways. Endocrinology 2004, 145:1550-1555

20. Zeidan A, Javadov S, Chakrabarti S, Karmazyn M: Leptin-induced cardiomyocyte hypertrophy involves selective caveolae and RhoA/ROCKdependent p38 MAPK translocation to nuclei. Cardiovasc Res 2008, 77:64-72.

21. Hilfiker-Kleiner D, Hilfiker A, Fuchs M, Kaminski K, Schaefer A, Schieffer B, Hillmer A, Schmiedl A, Ding Z, Podewski E, Podewski E, Poli V, Schneider MD, Schulz R, Park JK, Wollert KC, Drexler H: Signal transducer and activator of transcription 3 is required for myocardial capillary growth, control of interstitial matrix deposition, and heart protection from ischemic injury. Circ Res 2004, 95:187-195.

22. Jacoby JJ, Kalinowski A, Liu MG, Zhang SS, Gao Q, Chai GX, Ji L, Iwamoto Y, Li E, Schneider M, Russell KS, Fu XY: Cardiomyocyte-restricted knockout of STAT3 results in higher sensitivity to inflammation, cardiac fibrosis, and heart failure with advanced age. Proc Natl Acad Sci U S A 2003, 100:12929-12934.

23. Bates SH, Stearns WH, Dundon TA, Schubert M, Tso AW, Wang Y, Banks AS, Lavery HJ, Haq AK, Maratos-Flier E, Neel BG, Schwartz MW, Myers MG Jr: STAT3 signalling is required for leptin regulation of energy balance but not reproduction. Nature 2003, 421:856-859.

24. Toischer K, Rokita AG, Unsold B, Zhu W, Kararigas G, Sossalla S, Reuter SP, Becker A, Teucher N, Seidler T, Grebe C, Preuss L, Gupta SN, Schmidt K, Lehnart SE, Kruger M, Linke WA, Backs J, Regitz-Zagrosek V, Schäfer K, Field LJ, Maier LS, Hasenfuss G: Differential cardiac remodeling in preload versus afterload. Circulation 2010, 122:993-1003. 
25. Heida NM, Leifheit-Nestler M, Schroeter MR, Müller JP, Cheng IF, Henkel S, Limbourg A, Limbourg FP, Alves F, Quigley JP, Ruggeri ZM, Hasenfuss G, Konstantinides S, Schäfer K: Leptin enhances the potency of circulating angiogenic cells via src kinase and integrin (alpha)vbeta5: implications for angiogenesis in human obesity. Arterioscler Thromb Vasc Biol 2010, 30:200-206.

26. Ahima RS, Prabakaran D, Mantzoros C, Qu D, Lowell B, Maratos-Flier E, Flier JS: Role of leptin in the neuroendocrine response to fasting. Nature 1996, 382:250-252.

27. Purdham DM, Zou MX, Rajapurohitam V, Karmazyn M: Rat heart is a site of leptin production and action. Am J Physiol Heart Circ Physiol 2004, 287: $\mathrm{H} 2877-\mathrm{H} 2884$

28. McGaffin KR, Moravec CS, McTiernan CF: Leptin signaling in the failing and mechanically unloaded human heart. Circ Heart Fail 2009, 2:676-683.

29. Lollmann B, Gruninger S, Stricker-Krongrad A, Chiesi M: Detection and quantification of the leptin receptor splice variants $\mathrm{Ob}-\mathrm{Ra}, \mathrm{b}$, and, e in different mouse tissues. Biochem Biophys Res Commun 1997, 238:648-652.

30. Schroeter MR, Eschholz N, Herzberg S, Jerchel I, Leifheit-Nestler M, Czepluch FS, Chalikias G, Konstantinides S, Schäfer K: Leptin-dependent and leptin-independent paracrine effects of perivascular adipose tissue on neointima formation. Arterioscler Thromb Vasc Biol 2013, 33:980-987.

31. Ahrén B, Månsson S, Gingerich RL, Havel PJ: Regulation of plasma leptin in mice: influence of age, high-fat diet, and fasting. Am J Physiol Regul Integr Comp Physiol 1997, 273:R113-R120.

32. Abe Y, Ono K, Kawamura T, Wada H, Kita T, Shimatsu A, Hasegawa K: Leptin induces elongation of cardiac myocytes and causes eccentric left ventricular dilatation with compensation. Am J Physiol Heart Circ Physiol 2007, 292:H2387-H2396.

33. Purdham DM, Rajapurohitam V, Zeidan A, Huang C, Gross GJ, Karmazyn M: A neutralizing leptin receptor antibody mitigates hypertrophy and hemodynamic dysfunction in the postinfarcted rat heart. Am J Physiol Heart Circ Physiol 2008, 295:H441-H446.

34. Wang HT, Liu CF, Tsai TH, Chen YL, Chang HW, Tsai CY, Leu S, Zhen YY, Chai HT, Chung SY, Chua S, Yen CH, Yip HK: Effect of obesity reduction on preservation of heart function and attenuation of left ventricular remodeling, oxidative stress and inflammation in obese mice. J Trans/ Med 2012, 10:145.

35. Giandomenico G, Dellas C, Czekay RP, Koschnick S, Loskutoff DJ: The leptin receptor system of human platelets. J Thromb Haemost 2005, 3:1042-1049.

36. Thakker GD, Frangogiannis NG, Bujak M, Zymek P, Gaubatz JW, Reddy AK, Taffet G, Michael LH, Entman ML, Ballantyne CM: Effects of diet-induced obesity on inflammation and remodeling after myocardial infarction. Am J Physiol Heart Circ Physiol 2006, 291:H2504-H2514.

37. Smith CC, Mocanu MM, Davidson SM, Wynne AM, Simpkin JC, Yellon DM: Leptin, the obesity-associated hormone, exhibits direct cardioprotective effects. Br J Pharmacol 2006, 149:5-13.

38. Bouhidel O, Pons S, Souktani R, Zini R, Berdeaux A, Ghaleh B: Myocardial ischemic postconditioning against ischemia-reperfusion is impaired in ob/ob mice. Am J Physiol Heart Circ Physiol 2008, 295:H1580-H1586.

39. Barouch LA, Gao D, Chen L, Miller KL, Xu W, Phan AC, Kittleson MM, Minhas KM, Berkowitz DE, Wei C, Hare JM: Cardiac myocyte apoptosis is associated with increased DNA damage and decreased survival in murine models of obesity. Circ Res 2006, 98:119-124.

40. McGaffin KR, Zou B, McTiernan CF, O'Donnell CP: Leptin attenuates cardiac apoptosis after chronic ischaemic injury. CardiovasC Res 2009, 83:313-324.

41. Zheng J, Fang J, Yin YJ, Wang XC, Ren AJ, Bai J, Sun XJ, Yuan WJ, Lin L: Leptin protects cardiomyocytes from serum-deprivation-induced apoptosis by increasing anti-oxidant defence. Clin Exp Pharmacol Physiol 2010, 37:955-962.

42. McGaffin KR, Witham WG, Yester KA, Romano LC, O'Doherty RM, McTiernan CF, O'Donnell CP: Cardiac-specific leptin receptor deletion exacerbates ischaemic heart failure in mice. Cardiovasc Res 2011, 89:60-71

43. Hall ME, Smith G, Hall JE, Stec DE: Cardiomyocyte-specific deletion of leptin receptors causes lethal heart failure in Cre-recombinase-mediated cardiotoxicity. Am J Physiol Regul Integr Comp Physiol 2012, 303:R1241-R1250.
44. Sierra-Honigmann MR, Nath AK, Murakami C, Garcia-Cardena G, Papapetropoulos A, Sessa WC, Madge LA, Schechner JS, Schwabb MB, Polverini PJ, Flores-Riveros JR: Biological action of leptin as an angiogenic factor. Science 1998, 281:1683-1686.

45. Schram K, Wong MM, Palanivel R, No EK, Dixon IM, Sweeney G: Increased expression and cell surface localization of MT1-MMP plays a role in stimulation of MMP-2 activity by leptin in neonatal rat cardiac myofibroblasts. J Mol Cell Cardiol 2008, 44:874-881.

doi:10.1186/1479-5876-11-170

Cite this article as: Leifheit-Nestler et al:: Importance of leptin signaling and signal transducer and activator of transcription-3 activation in mediating the cardiac hypertrophy associated with obesity. Journal of Translational Medicine 2013 11:170.

\section{Submit your next manuscript to BioMed Central and take full advantage of:}

- Convenient online submission

- Thorough peer review

- No space constraints or color figure charges

- Immediate publication on acceptance

- Inclusion in PubMed, CAS, Scopus and Google Scholar

- Research which is freely available for redistribution

Submit your manuscript at www.biomedcentral.com/submit
Ciomed Central 